\title{
İnme Sonrası Dönemde Erişilebilir Ev Düzenlemelerinin Etkinliği
}

\author{
Effectiveness of Accessible Home Arrangements in the Post-Stroke Period
}

\author{
Didem GÖK NOKAY1(D), Gülşah KINALI (D) \\ ${ }^{1}$ Uzman Fizyoterapist, Bahçeşehir Üniversitesi, Lisansüstü Eğitim Enstitüsü, Fizyoterapi ve Rehabilitasyon Yüksek Lisans \\ Programı, İstanbul, Türkiye \\ ${ }^{2}$ Dr. Öğr. Üyesi, Sakarya Uygulamalı Bilimler Üniversitesi, Sağlık Bilimleri Fakültesi, Fizyoterapi ve Rehabilitasyon Bölümü, \\ Sakarya, Türkiye
}

\section{Öz}

\begin{abstract}
Amaç: Bu çalışmada inme sonrası iyileşmede erişilebilir ev düzenlemelerinin etkisinin incelenmesi amaçlandı. Gereç ve Yöntem: Adana Seyhan Devlet Hastanesi'ne akut inme ile başvuran 60 hasta çalışmaya dahil edildi ( $n=30$, kontrol grubu; $n=30$ çalışma grubu). Motor iyileşmeyi değerlendirmek için Brunnstrom değerlendirmesi, fonksiyonel seviyeyi belirlemek için Fonksiyonel Bağımsızlık Ölçeği, günlük yaşam aktivitelerini değerlendirmek için Barthel İndeksi ve depresyon düzeyini belirlemek için Beck Depresyon Envanteri kullanıldı. Ev erişilebilirlik değerlendirme ve düzenlemesi için, evrensel tasarım standartlarını ve günlük yaşam aktivite yardımcı malzemelerini içeren bir form oluşturuldu. Hasta ailesine evde yapılması gereken düzenlemeler hakkında eğitim verildi. Çalışma grubunda eğitim öncesi ve sonrası ev erişilebilirliği değerlendirildi, her iki grupta motor iyileşme, fonksiyonellik, günlük yaşam aktiviteleri ve depresyon düzeyi çalışma başlangıcında, 1. Ay sonunda ve 2. Ay sonunda değerlendirildi. Sonuçlar: Ev erişilebilirlik düzenlemesi yapılan çalışma grubunda üst ekstremite motor iyileşmesinde anlamlı bir değişiklik olmadı $(p=0,29)$. Alt ekstremite motor iyileşmesi $(p=0,01)$, fonksiyonel bağımsızlık düzeyi $(p=0,03)$, günlük yaşam aktiviteleri düzeyi $(p=0,04)$ istatistiksel olarak anlamlı derece arttı. Depresyon düzeyi ise istatistiksel olarak anlamlı derecede azaldı $(p=0,01)$. Tartışma: İnme sonrası dönemde hasta ve hasta yakınlarına ev erişilebilirlik düzenlemeleri eğitimi verilmelidir. Hastaneler bu konuda eğitim verebilecek uzmanları istihdam etmeli, evde bakım programlarının içine ev erişilebilirlik kontrolü, eğitimi ve düzenleme hizmetleri dahil edilmelidir
\end{abstract}

Anahtar Kelimeler: İnme; Ev Düzenlemeleri; Evrensel tasarım; Taburculuk; Erişilebilirlik.

\section{ABSTRACT}

\begin{abstract}
Purpose: In this study, it was aimed to examine the effect of accessible home arrangements on recovery after stroke. Material and Methods: Sixty patients admitted to Adana Seyhan State Hospital with acute stroke were included in the study ( $n=30$, control group; $n=30$ study group). Brunnstrom assessment was used to evaluate motor recovery, Functional Independence Scale was used to determine functional level, Barthel Index was used to evaluate activities of daily living, and Beck Depression Inventory was used to determine depression level. For home accessibility assessment and regulation, a form was created that includes universal design standards and daily living activity aids. The patient's family was educated about the arrangements to be made at home. Home accessibility was evaluated in the study group before and after the training. Motor recovery, functionality, activities of daily living and depression level were evaluated in both groups at the beginning of the study, at the end of the 1st month and at the end of the 2nd month. Results: There was no significant change in upper extremity motor recovery in the study group with home accessibility adjustment $(p=0.29)$. Lower extremity motor recovery $(p=0.01)$, functional independence level $(p=0.03)$, activities of daily living $(p=0.04)$ increased statistically significantly. Depression level decreased statistically significantly $(\mathrm{p}=0.01)$. Discussion: In the post-stroke period, education on home accessibility arrangements should be given to patients and their relatives. Hospitals should employ experts who can provide training on this subject, and home accessibility control, training and regulation services should be included in home care programs.
\end{abstract}

Keywords: Stroke; House Arrangements; Universal design; Discharge; Accessibility

Sorumlu Yazar (Corresponding Author): Gülşah KınalıE-mail: gulsah.kinali@gmail.com ORCID ID: 0000-0001-7974-5571

Geliş Tarihi (Received): 31.10.2020; Kabul Tarihi (Accepted): 07.12.2021

Bu çalışma, 21-22 Aralık 2019 tarihlerinde İstanbul'da düzenlenen ‘5. Uluslararası Mühendislik Mimarlık ve Tasarım’ Kongresinde sözlü bildiri olarak sunulmuştur. 
Inme, dünyada önemli bir mortalite ve engellilik nedenidir (Norrving ve Kissela, 2013). İnme deneyimi olan kişilerin önemli fiziksel, bilişsel ve duygusal sorunları vardır. Hastaların \%25-30'u günlük yaşam ve öz bakım aktivitelerinde kısmen veya tamamen bağımlıdır (Miller ve ark., 2010). İnme sonrası dönemde eğitim, sosyal destek, tıbbi bakım ve rehabilitasyon hastalar ve bakım verenleri ile için vazgeçilmez haklardır (Li ve ark., 2017). Aileleri ve bakım verenleri rollerine hazırlamak gerekir. Temel adım, destekleyici bir programla yeterli bilgiyi sağlamaktır (Oupra ve ark., 2010). İnmeli kişilerde erken ev destekli taburculuk programları Avrupa ülkelerinde uygulanmaya başlanmış ve etkili olduğu gösterilmiştir. Hastane ve ev arasındaki geçişi iyileştirmeye ve bu özel programı geliştirmeye intiyaç vardır. İyi organize edilmiş multidisipliner ekipler tarafından sağlanan program, hastalarda uzun vadeli bağımsızlığı kolaylaştırabilir. Özellikle inme ünitesinin bakımıyla birleştirildiğinde, eşdeğer veya daha düşük maliyetlerle daha iyi sağlık sonuçları sağlanabilir (Santana ve ark., 2017).

Tam bir iyilik hali ve öz kimlik oluşturmak amacı ile engellilerin günlük hayata katııımı teşvik edilmelidir. İş, aile ve toplum gibi farklı alanlara katıım, tam bir iyilik hali veya öz kimlik oluşturmak için çok önemlidir (Bergström ve ark., 2015; Reinhardt ve Stucki, 2007). İnme sonrası 6 aydan 4 yıla kadar katıım seviyeleri hala sınırlı olabilir (Sturm ve ark., 2002; Sturm ve ark., 2004). Katılım sorunları çoğunlukla fiziksel bağımsızlık, hareketlilik ve meslekler/hobiler alanlarıla ilgilidir (Palstam ve ark., 2019).

Günlük aktivitelere katılımda çevresel faktörler belirleyicidir (Keysor ve ark., 2006). Tıbbi ve sosyal modellerin bir kombinasyonu olan Uluslararası İşlevsellik ve Engellilik Sınıflandırması, vücudun yapısı, işlevi ve yaşamdaki faaliyetlere odaklanır. Bireyin yaşamını temsil eden bağlamsal faktörler, çevresel ve kişisel olarak ikiye ayrılır (Wee, 2009; Rochette ve ark., 2001). Uluslararası İşlevsellik, Engellilik ve Sağlık Sınıflandırmasının çevre alanı, fiziksel ve fiziksel olmayan bir ortamdan oluşur. Bu ortamlar, yaşam ortamını oluşturan sosyal ve davranışsal faktörleri içerir. Fiziksel çevrenin etkisi, toplum ortamının değerlendirilmesi açısından esastır. Fiziksel ortamdan dolayı evde veya işyerinde çeşitli güvenlik tehlikeleri ve tasarım zorlukları ortaya çıkabilir. Bu zorluklar sosyal katıımın önünde bir engel olabilir (Akulwar ve Shahane,
2017).

İnme sonrası dönemde insanlar kendi evlerinde yaşamayı sürdürmek ve toplumun bir parçası olmak için isteklidirler. Bu nedenle evlerin evrensel tasarıma uygunluğu her zaman önemlidir. Evlerde evrensel tasarım, uygun bir rampa ve tuvalet, korkuluk gibi girişleri içermelidir (Ellis-Hill ve Horn, 2000; Sanford, 2012). Türkiye'de Aile ve Sosyal Politikalar Bakanlığı'nın erişilebilirlik ile ilgili çalışmaları bulunmaktadır, bu kapsamda erişilebilirlik standartları ile ilgili bir rehber yayınlanmıştır (Çiftçi ve Çağlayan, 2017)

Fonksiyonel iyileşmeyi sağlamak için multidisipliner ekip çalışması yapılsa da inme sonrası dönemde fonksiyonel durumun azalması nedeniyle hastalar halen zorluklarla karşılaşmaktadır. Depresyon, sosyal izolasyon ve düşük fonksiyonel durum, eve taburcu olurken var olabilecek zorluklar olarak sayılabilir (Wood ve ark., 2010; Hugues ve ark., 2017). Bu duruma denge kaybı, düşme, ikincil depresyon ve bası yaraları gibi komplikasyonlar da eşlik edebilir (Wood ve ark., 2010; Hugues ve ark., 2017; Huang ve ark., 2017; Chun ve ark.,2018).

Kişiler açısından planlı taburculuk komplikasyonları azaltabilir ve öz yeterliliği artırabilir (Wilson ve ark., 2017). Buna göre ev düzeni taburculuk sürecinde önemli bir parametredir (Kylén ve ark., 2019). Hasta merkezli ve standart bir taburculuk programı, inme hastalarının topluma yeniden katıımını kolaylaştıır. Bu program günlük yaşam performansını ve yaşam kalitesini iyileştirebilir. Hastaneden eve sağlıkı bir geçiş de hastalığın tekrarlama oranını azaltabilir (Drummond ve ark., 2012; Miller ve ark., 2019).

Erişilebilirlik ve ev düzenlemeleri, ev ortamında inme rehabilitasyonunda öne çıkan kolaylaştırıcı yöntemler olabilir. Tek kat seviyesinde düzenlenen açık alan çözümleri, inme rehabilitasyon sürecinde en etkili yöntemdir. Ev düzeni değişiklikleri, eşiklerin kaldırılması, kaymaz zemin yüzeyleri ve korkuluklar diğer faydalı ve basit çözümler olarak sayılabilir. Tekerlekli sandalyeler, yürüme yardımcıları, banyo yardımcıları, yüksek tuvaletler ve hareket rampaları gibi yardımcı cihazlar inme rehabilitasyon sürecinin kolaylaştııcıları olarak kabul edilir ve erişilebilirliğe katkıda bulunur (Marcheschi ve ark., 2018). Ev düzenlemeleri sadece inme sonrası dönemde değil, yaşlanma gibi durumlarda da önemlidir (Garin ve ark., 2014). Son yıllarda evrensel tasarım yaklaşımı bir öncelik kazanmıştır. Evrensel tasarım, yaş, beceri ve durum farkı olmaksızın, herkes tarafından tüm ürün ve çevrelerin kullanılabilmesini amaçlayan bir yaklaşımdır (Kınalı, 2020). Mekansal tasarıma evrensel tasarım 
ilkeleri uygulandığında, inme sonrası dönemde ek düzenleme yapılması gerekmeyebilir. İnmeli yaşlılar için de evrensel tasarımla ev düzenlemesi yapılması gerekebilir (Werngren-Elgström ve ark., 2009).

İnme hem motor bozukluğa neden olan hem de bireylerin fonksiyonellik ve bağımsızlığını azaltan bir durumdur. Bağımlı olma duygusu ile gelişen depresyon da inme sonrası dönemde karşılaşılan önemli bir problemdir. Depresyon hem bir sonuç hem de tedavi sürecini zorlaştırabilecek bir nedendir (Lenzi ve ark., 2008). Bu nedenle, inme rehabilitasyonu ve taburculuk sırasında evde yapılan düzenlemelerin motor iyileşme, fonksiyonel bağımsızlık ve depresyon üzerine etkisini belirlemeyi amaçladık.

\section{GEREÇ VE YÖNTEM}

Araştırmaya Adana Seyhan Devlet Hastanesi'nde yatan, akut serebro vasküler olay teşhisi bulunan 30-70 yaş arası 63 gönüllü katılımcı katıldı. Toplamda 60 katılımcı ile çalışma tamamlandı. Çalışmaya dahil edilme Kriterleri; 30-70 yaş aralığında olmak, söyleneni anlayacak, yer ve zamanı ayırt edecek kadar koopere olmak ve 0-6 ay önce inme geçirmiş olmak olarak belirlendi. Dahil edilmeme kriterleri ise; kontrolsüz hipertansiyonu olmak, değerlendirme sırasında soruları anlamamak, eğitimi anlamamak, yeni bir inme geçirmek ve yeni bir inme geçirmeye neden olabilecek kalp hastalıklarına (aritmi, anjina pektoris vb.) sahip olmak olarak belirlendi. Kontrol grubundaki bireylerin aileleri, evlerinin fiziksel olarak erişilebilir ev düzenlemelerinin uygulanması için uygun olmadığını belirtti.

Çalışmanın güç analizi G* Power 3.1.7 programı ile yapıldı ve örneklem sayısı $n=60$ olarak belirlendi. Araştırmada deneysel desen kullanılması nedeniyle örneklem sayısı zaman ve maliyet açısından sınırlı tutuldu. Çalışmanın gücü 0,95 , etki büyüklüğü düzeyi ise 0,45 olarak belirlendi.

\section{Veri Toplama Araçları}

$\mathrm{Bu}$ çalışma bağımsız, eş zamanlı kontrollü deneysel bir çalışma olarak tasarlandı. Katılımcıların yaş, cinsiyet, eğitim düzeyi ve meslekleri kaydedildi. Tıbbi öykü ve ek sistemik hastalıklar değerlendirildi. İnme sonrası hemipleji tarafı (sağ/sol) kaydedildi. Değerlendirme sırasında hastanın optimal performans gösterebileceği ve teste odaklanabileceği saatler dikkate alındı. Hastalar hareketsiz olduğu için boykilo ölçümü alınamadı. Hem çalışma hem de kontrol grupları değerlendirmelere tabi tutulmuştur. Ev düzenlemesi çalışmasına katılmak isteyen 30 kişiye ev düzenlemesi eğitimi verildi. Çalışma grubunda eğitim öncesi ve sonrası ev erişilebilirliği değerlendirildi, her iki grupta motor iyileşme, fonksiyonellik, günlük yaşam aktiviteleri ve depresyon düzeyi çalışma başlangıcında, 1. Ay sonunda ve 2. Ay sonunda değerlendirildi (Altuntaş ve Kayıhan 2015; Ellis-Hill ve Horn, 2000).

Motor iyileşmeyi değerlendirmek için Brunnstrom nörofizyolojik değerlendirmesi kullanıldı (Evre 1: Hemiplejik taraf flask, aktif hareket yok, kol sinerji paternlerinde hareket ettirildiğinde, pasif harekete direnç yok veya azdır. Evre 2: İstemli harekete başlama isteği ile sinerji paternleri belirir. Evre 3: Spastisite belirginleşmiştir. İzole hareket yapılamaz. Evre 4: Hareket sinerjilerinde farklı izole hareketler başlamıştır. Spastisite nispeten azalmış fakat izole hareketler ile devam etmektedir. Evre 5: Spastisite azalmaktadır. İzole hareketler kolaylaşmıştır. Evre 6: İzole eklem hareketleri yapabilir, koordinasyon iyidir ancak halen ufak sapmalar olabilir) (Öncü ve ark., 2014). Fonksiyonel durum, fonksiyonel bağımsızlık ölçeği ile değerlendirilmiştir. Bu ölçek; kendine bakım, sifinkter kontrolü, mobilite, lokomosyon, iletişim ve sosyal iletişim bölümlerinden oluşmaktadır. Yedi Puan tam bağımsızlığı, 1 puan ise tam yardımlı durumu ifade eder. Toplam puanlama 18-126 arasında değişmektedir (Soyuer, 2007). Günlük yaşam aktivitelerindeki bağımsızlık Barthel İndeksi ile değerlendirildi. Barthel indeksinin puanları 0-100 arasında değişmekte, 0-20 puan; tamamen bağımlıığı, 21-61 puan; ileri derecede bağımlılığı, 62-90 puan; orta derecede bağımlıı̆̆ı, 91-99 puan; hafif derecede bağımlılığı, 100 puan; bağımsızlığı işaret etmektedir (Mollaoğlu ve ark., 2011). Çalışmamızda puanlar derecelendirme kullanılmaksızın kayıt edildi. Depresyon durumunu değerlendirmek için Beck Depresyon Envanteri kullanıldı, sorulara verilen cevaplar ölçeğin belirttiği şekilde 0-3 arası puanlandı ve toplandı. 0-9 arası puan minimal depresyon, 10-16 arası puan hafif depresyon, 17-29 arası puan orta şiddette depresyon ve 30-63 arası puan şiddetli depresyon olarak kabul edilmektedir. Çalışmamızda, depresyon seviyesi ile ilgili derecelendirme kullanılmaksızın yalnızca puan kayıt edildi. (Beck ve ark., 1996; Hormozi ve ark., 2019; Ahmed ve ark., 2003; Fydrich ve ark., 1992).

Müdahale: Ev erişilebilirlik değerlendirme ve düzenlemesi için, literatürdeki çalışamlar incelenerek evrensel tasarım standartlarını ve günlük yaşam aktivite yardımcı malzemeleri içeren bir form oluşturuldu. Hasta ve ailesine ev düzenlemeleri konusunda eğitim verildi. Ev düzenleme eğitiminde, 
evrensel tasarım ilkelerine uygun ev düzenleme prensipleri anlatıldı. Hasta yataklarının odaya yerleştirilme ve konumlandırma ilkeleri, tuvalet yüksekliği, evin girişinde bulunması gereken rampaların fiziksel özellikleri, kapıların genişlikleri ve tırabzanların fiziksel özellikleri, merdiven basamak yükseklikleri ve priz seviyeleri konusunda erişilebilirlik standartlarına uygun bilgiler verildi. Günlük yaşam aktivitelerinde kullanımı kolaylaştırmak için pipet, kol-bacak taşıma aparatı ve omuz askısı kullanımı anlatıldı. Evin yeterli aydınlatılması önerildi. Hastanın güvenliğini sağlayan sandalye ve masa tercihleri anlatıldı. Ayrıca banyoda kaymaz paspas kullanılması, halıların zemine sabitlenmesi, eşiklerin kaldırılması gerektiği açıklandı (Sanford, 2012). Hasta-aile eğitimi ve çalışma öncesi değerlendirme için ev düzenlemesi için gerekli maddelerini içeren form kullanıldı. Hem kontrol hem de çalışma grubu hastaları evde değerlendirildi. Her iki grupta da çalışma öncesinde fiziksel ev düzenlemelerine ve yardımcı ekipmanlara uyum konusunda farkındalık yoktu. Ev düzenleme çalışmasına katılmaya gönüllü olan 30 hasta ve ailelerine gerekli fiziksel düzenlemelerin yapılması konusunda eğitim verildi. Çalışma grubu düzenlemeleri tam olarak uyguladı.

\section{Etik Boyutlar}

Bu çalışma için T.C. Adana Valiliği, İı Sağlık Müdürlüğü 27350520/799 sayılı bilimsel çalışma izni ve T.C. Çukurova Üniversitesi Tıp Fakültesi Girişimsel OImayan Klinik Araştırmalar Etik Kurulundan, 2 Şubat 2018 Tarihli 74/15 sayılı kararı ile onay alınmıştır.

İstatistiksel Analiz

Hastaların ölçümleri ortalama, standart sapma, frekans ve yüzde olarak hesaplandı. Çalışma gruplarını demografik düzeyde karşılaştırmak için ki-kare testi kullanıldı. Çalışma gruplarına göre hastaların birinci ve ikinci ay ölçümleri arasındaki farkı incelemek için MannWhitney U testi yapıldı. Gruplarda birinci ve ikinci ay düzeylerinde ölçümlerin farklı düzeylerde olup olmadığının araştırıması Wilcoxon işaret testi ile yapıldı. Çalışmada kritik karar verme değeri <0,05 olarak seçilmiştir. Analizler SPSS 22.00 paket programı ile yapılmıştır.

\section{SONUÇLAR}

Çalışmada grupların demografik bilgileri incelendiğinde, çalışma ve kontrol gruplarının cinsiyet dağılımlarının benzer seviyelerde olduğu görüldü. Eğitim seviyeleri de önemli ölçüde farklı değildi. Meslek dağılımına bakıldığında da grupların benzer düzeyde olduğu görülmektedir. Hemiplejik taraf (sağ/sol) dağılımları farklı düzeylerde değildi. Grupların yaş dağılımı anlamlı olarak farklı değildi. Gruplar cinsiyet, eğitim, meslek, hemiplejik taraf ve yaş açısından homojendi (Tablo 1).

Tablo 1. Grupların demografik bilgileri

\begin{tabular}{lllll}
\hline Tanımlayıcı & & $\begin{array}{l}\text { Çalışma } \\
\text { Grubu }(\mathbf{n = 3 0})\end{array}$ & $\begin{array}{l}\text { Kontrol Grubu } \\
(\mathbf{n = 3 0})\end{array}$ & P \\
\cline { 2 - 4 } & & $\mathbf{n}(\%)$ & $\mathbf{n}(\%)$ & 0,09 \\
\hline Cinsiyet & Erkek & $16(53,3)$ & $18(40,0)$ & 0,23 \\
& Kadın & $14(46,7)$ & $23(76,7)$ & \\
\hline Eğitim Seviyesi & İlkokul & $24(80,0)$ & $1(3,3)$ & 0,14 \\
& Ortaokul & $3(10,0)$ & $6(20,0)$ & -() \\
\hline Meslek & Lise & $2(6,7)$ & $4(13,3)$ & 0,07 \\
& Üniversite & $1(3,3)$ & $8(26,7)$ & $18(60,0)$ \\
& Çiftçi & $8(26,7)$ & -() & 0,14 \\
\hline Hemipleji Yönü & Esnaf & $7(23,3)$ & $1(3,3)$ & \\
& Ev hanımı & $14(46,7)$ & $29(96,7)$ & \\
\hline Yaş (yıl) & Sporcu & $1(3,3)$ & $66,20 \pm 5,78(18-52)$ & \\
& Sağ & $3(10,0)$ & & \\
\hline
\end{tabular}


Tablo 2. Kontrol ve çalışma gruplarında 1.ve 2. Ay değerlendirme sonuçları

\begin{tabular}{|c|c|c|c|c|c|}
\hline \multirow[t]{3}{*}{ Ölçüm } & \multirow[t]{3}{*}{ Ay } & \multirow{2}{*}{\multicolumn{2}{|c|}{$\begin{array}{l}\text { Kontrol } \\
\text { Grubu }(n=30)\end{array}$}} & \multirow{2}{*}{\multicolumn{2}{|c|}{$\begin{array}{l}\text { Çalışma } \\
\text { Grubu }(n=30)\end{array}$}} \\
\hline & & & & & \\
\hline & & $\mathrm{X} \pm \mathrm{SD}$ & $\mathrm{p}$ & $\mathrm{X} \pm \mathrm{SD}$ & $\mathrm{p}$ \\
\hline Brunnstrom Üst Ekstremite & 1. ay & $2,77 \pm 1,45$ & $0,01^{*}$ & $2,37 \pm 1,63$ & $0,01^{*}$ \\
\hline Derecelendirmesi & 2. ay & $3,83 \pm 1,18$ & & $3,77 \pm 1,36$ & \\
\hline Brunnstrom Alt Ekstremite & 1. ay & $2,63 \pm 0,93$ & $0,01^{*}$ & $2,87 \pm 1,36$ & $0,01^{*}$ \\
\hline Derecelendirmesi & 2. ay & $3,87 \pm 0,82$ & & $4,33 \pm 1,09$ & \\
\hline Fonksiyonel & 1. ay & $47,97 \pm 18,28$ & $0,01^{*}$ & $52,63 \pm 23,9$ & $0,01^{*}$ \\
\hline Ölçeği & 2. ay & $77,37 \pm 23,48$ & & $87,4 \pm 24,12$ & \\
\hline \multirow[t]{2}{*}{ Barthel İndeksi } & 1. ay & $34,67 \pm 25,05$ & $0.01^{*}$ & $27,83 \pm 29,79$ & $0,01^{*}$ \\
\hline & 2. ay & $67,67 \pm 23,29$ & & $73,00 \pm 22,88$ & \\
\hline \multirow[t]{2}{*}{ Beck Depresyon Envanteri } & 1. ay & $35,27 \pm 9,05$ & $0,01^{*}$ & $39,67 \pm 13,89$ & $0,01^{*}$ \\
\hline & 2. ay & $22,40 \pm 9,08$ & & $14,07 \pm 9,40$ & \\
\hline
\end{tabular}

*0,05 düzeyinde önemli fark

Kontrol grubunda 2. ay ölçümlerinde 1. ay ölçümlerine göre üst ekstremite motor iyileşmesi, alt ekstremite motor iyileşmesi, fonksiyonel bağımsızlık düzeyi, günlük yaşam aktiviteleri düzeyi anlamlı derecede arttı, depresyon düzeyi ise anlamlı ölçüde azaldı. Çalışma grubunda da 2. ay ölçümlerinde 1. ay ölçümlerine göre üst ekstremite motor iyileşmesi, alt ekstremite motor iyileşmesi, fonksiyonel bağımsızlık düzeyi, günlük yaşam aktiviteleri düzeyi anlamlı derecede arttı, depresyon düzeyi ise anlamlı ölçüde azaldı (Tablo 2).
Çalışma grubunda, 1. ayın sonunda, üst ekstremite motor iyileşme düzeyi, fonksiyonel bağımsızlık düzeyi, günlük yaşam aktiviteleri düzeyi ve depresyon düzeyi kontrol grubuna göre anlamlı bir değişiklik göstermedi. 2. ayın sonunda ise çalışma grubunda alt ekstremite motor iyileşme düzeyi, fonksiyonel bağımsızlık düzeyi, günlük yaşam aktiviteleri düzeyi kontrol grubuna göre anlamlı düzeyde artmıştı, depresyon düzeyi ise anlamlı olarak azalmıştı. 2. ayın sonunda çalışma grubunda üst ekstremite iyileşme düzeyi kontrol grubuna göre anlamlı derecede farklılık göstermedi (Tablo 3). 
Tablo 3. Kontrol ve çalışma grupları arasında 1. ve 2. Ay değerlendirme sonuçlarının karşılaştırılması

\begin{tabular}{|c|c|c|c|c|c|c|}
\hline \multirow[t]{3}{*}{ ÖIçüm } & \multicolumn{2}{|c|}{ 1. Ay Ölçümü } & \multicolumn{3}{|c|}{ 2. Ay Ölçümü } & \multirow[b]{2}{*}{$p$} \\
\hline & $\begin{array}{l}\text { Kontrol } \\
\text { Grup } \\
(n=30)\end{array}$ & $\begin{array}{l}\text { Çalışma } \\
\text { Grubu } \\
(n=30)\end{array}$ & $P$ & $\begin{array}{l}\text { Kontrol } \\
\text { Grubu } \\
(n=30)\end{array}$ & $\begin{array}{l}\text { Çalışma } \\
\text { Grubu } \\
(n=30)\end{array}$ & \\
\hline & $\mathrm{X} \pm \mathrm{SD}$ & $\mathrm{X} \pm \mathrm{SD}$ & & $\mathrm{X} \pm \mathrm{SD}$ & $\mathrm{X} \pm \mathrm{SD}$ & \\
\hline $\begin{array}{l}\text { Brunnstrom Üst } \\
\text { Ekstremite } \\
\text { Derecelendirmesi }\end{array}$ & $2,77 \pm 1,45$ & $2,37 \pm 1,63$ & 0,26 & $3,83 \pm 1,18$ & $3,77 \pm 1,36$ & 0,29 \\
\hline $\begin{array}{l}\text { Brunnstrom Alt } \\
\text { Ekstremite } \\
\text { Derecelendirmesi }\end{array}$ & $2,63 \pm 0,93$ & $2,87 \pm 1,36$ & 0,34 & $3,87 \pm 0,82$ & $4,33 \pm 1,09$ & $0,01^{*}$ \\
\hline $\begin{array}{l}\text { Fonksiyonel } \\
\text { Bağımsızlık Ölçeği }\end{array}$ & $47,97 \pm 18,28$ & $52,63 \pm 23,9$ & 0,21 & $77,37 \pm 23,48$ & $87,4 \pm 24,12$ & $0,03^{*}$ \\
\hline Barthel İndeksi & $34,67 \pm 25,05$ & $27,83 \pm 29,79$ & 0,16 & $67,67 \pm 23,29$ & $73,00 \pm 22,88$ & $0,04^{*}$ \\
\hline $\begin{array}{l}\text { Beck Depresyon } \\
\text { Envanteri }\end{array}$ & $35,27 \pm 9,05$ & $39,67 \pm 13,89$ & 0,29 & $22,40 \pm 9,08$ & $14,07 \pm 9,40$ & $0,01^{*}$ \\
\hline
\end{tabular}

*0,05 düzeyinde önemli fark

\section{TARTIŞMA}

İnme rehabilitasyonu uzun, zorlu ve dinamik bir süreçtir. Taburcu olma süreci, gerçek hayata dönüşün ilk adımıdır. Bu süreç fonksiyonel ve duygusal kayıplara yol açar. Bu nedenle, literatürde inme sonrası dönemde yaşama tekrar dönüş, depresyonun etkileri, denge kayıpları üzerine çalışmalar yürütüldüğü görülmektedir (Wood ve ark., 2010; Hugues ve ark., 2017; Huang ve ark., 2017; Chun ve ark., 2018). Son dönemlerde inme rehabilitasyonunda, robotik rehabilitasyon gibi yenilikçi çözümler de kullanılmaya başlamıştır (Kınalı, 2017). Fakat rehabilitasyon süreci hastane ile sınırlı bir süreç değildir. Erişilebilirlik ve evrensel tasarım uygulamaları toluma katılımın iki anahtarıdır (Kınalı, 2020). Bu nedenle bu çalışmada ev düzenlemelerinin taburculuk sonrası rehabilitasyon, motor iyileşme, fonksiyonel bağımsızlık ve depresyon üzerindeki etkisini belirlemeyi amaçladık.

Çalışmamızda inmeli hastalara nörofizyolojik tedavi öncesi ev düzenlemeleri hakkında bilgi verildi. Çalışmamız, dünya çapında inme rehabilitasyonunda uygulanmakta olan erken taburculuk programlarına ev düzenlemelerinin dahil edilmesine bir örnektir.
Sonuçlarımız, inme sonrası erken ev erişilebilirlik düzenlemesi uygulanan hastalarda 2. Ay yapılan ölçümlerde alt ekstremite motor iyileşmesi, fonksiyonel bağımsızlık ve günlük yaşam aktiviteleri düzeyinde artma, depresyonda ise azalma olduğunu gösterdi. Üst ekstremite motor iyileşmesinde anlamlı bir değişiklik olmadı. İnme sonrası üst ekstremite motor iyileşmesinin zoruluğu bilinmektedir. İnme sonrası uygulanan rehabilitasyon programlarına rağmen üst ekstremitede ve elde kalıcı motor defisitlerle karşılaşılmaktadır (Yavuzer G. ve ark., 2001). Bu durumda çalışmamızın sonucunun literatür ile uyumlu olduğunu söyleyebiliriz. Bizim çalışmamız taburculuk sonrası 2 aylık bir süreyi kapsıyordu. Bu nedenle, erişilebilir ev düzenlemelerinin üst ekstremite motor iyileşmesine de etkilerini değerlendiren ve daha uzun süreli izleme yapan çalışmalara halen ihtiyaç olduğunu düşünüyoruz.

Cameron ve ark.'a göre inmenin çok boyutlu sonuçlarını tanımak için odak, akut bakım ortamlarından, rehabilitasyon ve toplum ortamlarına genişletilmelidir (Cameron ve ark., 2008). Rochette ve arkadaşlarına göre, fiziksel ve sosyal çevrede algılanan engeller inme sonrası engelliliğe katkıda bulunur. Ayrıca depresyon sonuçları topluma katılımı azaltan bir faktör olarak yeti yitimine neden olabilir (Rochette ve ark., 2001). Bizim çalışmamızda erişilebilir bir ev düzenlemesi yapıldığında depresyon düzeyleri anlamlı 
olarak azaldı, motor ve fonksiyonel iyileşme ise arttı. Bu durumda fiziksel engellerin azaltılmasının engelliliği azalttığını biz de söyleyebiliriz.

Keysor ve ark. çevresel engellerin genel rehabilitasyona katılımı etkilediğini belirtti (Keysor ve ark., 2006). Ev düzenlemeleri, depresyonun şiddetini azaltarak rehabilitasyona katkıda bulunabilir. Çevresel engeller inme sonrası fonksiyonel kaybın daha şiddetli hissedilmesine neden olur. Yetersizlik duygusu hastayı depresyona iter (Ahmed ve ark., 2003). Bu nedenle, çalışmamızda erişilebilir ev düzenlemelerinin inme sonrası dönemde etkinliğini incelemeyi amaçladık. Bizim çalışmamızın sonucunda da depresyon düzeyinde anlamlı azalma oldu, bu durum erişlebilir bir evin inme sonrası bireyleri daha bağımsız hale getirdiği ve depresyon düzeyini düşürdüğü olarak yorumlanabilir. Önleyici ve tedavi edicistratejilerin uygulanması, ruh hali değişimleri riskini azaltabilir. Bu nedenle, inme hizmetlerinin organizasyonunda rehabilitasyon sonuçlarının iyileştirilmesi esastır. Lenzi ve arkadaşlarına göre depresyon, inme sonrası en sık görülen komplikasyondur. Depresyonun erken tedavisi, sadece depresif belirtiler üzerinde değil, aynı zamanda inmeli hastaların rehabilitasyon sonuçları üzerinde de olumlu bir etkiye sahip olabilir. Bununla birlikte, depresyonu önlemede antidepresanların veya psikoterapinin yararlı olduğuna dair bir kanıt yoktur (Lenzi ve ark., 2008). Çalışmamızda, klasik nörofizyolojik rehabilitasyona ek olarak uygulanan bir ev erişilebilirlik düzenleme programı, 2. ay sonunda, çalışma grubunda kontrol grubuna göre depresyon düzeyini önemli ölçüde azaltmıştır. Bu bağlamda ev düzenlemeleri inme sonrası depresyonun önlenmesinde önemli bir müdahale olarak değerlendirilebilir. Altuntaş ve Kayıhan ev düzenlemelerinin yaşlılarda depresyon düzeyini etkilemediğini göstermiştir (Altuntaş ve Kayıhan, 2015). Bizim çalışma grubumuzda ise depresyon düzeyi hem grup içi hem de gruplar arası karşılaştırmalarda anlamlı düzeyde azalmıştır. Bizim çalışmamız daha geniş bir yaş aralığını kapsıyor ve inmeli hastaları içeriyordu. $\mathrm{Bu}$ bakımdan inme sonrası taburculuk döneminde uygulanan ev düzenleme eğitimi ve uygulamalarının, inme sonrası depresyonla mücadelede bir adım olabileceğini düşünüyoruz.

Altuntaş ve ark. ev düzenlemelerinin yaşlılarda yaşam kalitesini ve ev güvenliğini artırdığını bulmuştur (Altuntaş ve Kayıhan, 2015). Bizim çalışmamız da, erken ev düzenlemesi yapılan hastalarda fonksiyonel bağımsızlık durumu ve günlük yaşam aktiviteleri performansının anlamlı olarak arttığını gösterdi. Bu açıdan çalışmamız literatürle uyumludur.

Literatürde inme sonrası hastanın taburcu edilmesini hızlandırmayı ve kendi evinde hastaneye eşdeğer bir rehabilitasyon düzeyine ulaşmayı amaçlayan erken destekli taburculuk programlarının etkinliğinden bahsedilmiştir (Langhorne ve WidenHolmqvist, 2007). Çalışmamızda evde taburculuk programına nörofizyolojik rehabilitasyonun yanı sıra ev düzenlemelerinin eğitimi ve kontrolü de eklenmiştir. Hareketin fonksiyonel kaybı, inmenin yaygın bir sonucudur. İnmeyi yönetmek için çok çeşitli müdahaleler geliştirilmiştir. İnme sonrası motor toparlanma için, literatürde kısıtlı hareket terapisi, elektromiyografik geri bildirim, tekrarlayan görev eğitimi, fiziksel uygunluk eğitimi ve yüksek yoğunluklu terapi (genellikle fizyoterapi) olan çeşitli tedavi yöntemleri örnek gösterilmiştir. Özellikle, yüksek yoğunluklu ve tekrarlayan göreve özgü uygulamalar, motor iyileşme sürecine katkıda bulunur (Langhorne ve ark., 2009). Çalışmamızda ev düzenlemesinin yanı sıra Brunnstrom yöntemi ile nörofizyolojik tedavi de uygulandı. Çalışmamızın sonucunda klasik nörofizyolojik tedavi uygulanan hastalarda da tüm parametrelerde anlamlı derece iyileşme görülmüştü ancak erişilebilir ev düzenlemeleri uygulandığında bu iyileşme seviyesi çalışma grubunda kontrole göre daha yüksek bulundu. Yalnızca erişilebilir ev düzenlemesi ilave uygulaması üst ekstremite iyileşmesinde anlamlı bir yükselmeye neden olmadı. Çalışmamızın sonucuna göre erişilebilir ev düzenlemelerinin klasik nörofizyolojik rehabilitasyon yöntemlerine ilave olarak kullanılmasını öneriyoruz.

Çalışmamızdaki limitasyon zaman çizelgesiydi. İnmeden sonraki ilk yıl motor iyileşme için önemlidir. Çalışmamız erken taburculuk programını incelediğiiçin 1 yıl sonra motor toparlanmanın nasıl değiştiğini gözlemlemek mümkün olmadı. Ev düzeninin motor iyileşme üzerindeki etkisini incelemek için daha uzun çalışmalara intiyaç vardır.

Paci ve arkadaşlarına göre hemorajik hemiplejik hastalarda, üst ve alt ekstremite motor toparlanma hızları arasında fark yoktu (Paci ve ark., 2016). Duncan ve arkadaşlarına göre ise alt ekstremite motor iyileşmesi üst ekstremiteden daha hızlıdır (Duncan ve ark., 1992). Literatürde eş zamanlı olarak izlenen ev düzenlemesi ve nörofizyolojik tedavinin üst ve alt motor iyileşme üzerine etkileri net değildi. $\mathrm{Bu}$ nedenle çalışmamız özgün bir yaklaşıma sahip olabilir. Çalışmamızın sonucunda göre erişilebilir ev düzenlemeleri yapılan çalışma grubunda da alt 
ekstremite motor iyileşmesi üst ekstremiteye göre daha hızlı idi. Bu durum literatür ile uyumlu idi. Üst ekstremitenin motor iyileşmesindeki etkinliği gözlemlemek için daha uzun süreli izleme yapan çalışmaların yapılmasını öneriyoruz.

Sonuç olarak, ev içi düzenleme eğitimi ve evrensel standartlara dayalı uygulamalar inme sonrası dönemde inme sonrası depresyonu azaltmaktadır. Eve dönüş, inme sonrası dönemde yaşama katımanın ilk adımıdır. İnme sonrası depresyonun, sosyal katılımı etkileyen önemli bir sorun olduğu düşünüldüğünde, inme sonrası ev düzenlemeleri depresyonu azaltabilir ve hastanın sosyal katıımını artırabilir. Çalışmamıza göre taburculuk döneminde erken erişilebilirlik ve evrensel tasarım uygulamaları fonksiyonel iyileşme üzerine de olumlu bir etkiye sahiptir. Bu nedenle taburculuk programlarına erişilebilir ev uygulamalarının dahil edilmesini gerekli görüyoruz.

Yetersiz çevresel düzenlemeler, sadece hastaların değil bakım verenlerin de ergonomik zorluklar yaşamasına neden olabilir. Farklı hastalık gruplarında da bakım verenlerkas-iskelet sistemi hastalıklarından yakınmaktadır (Kınalı ve Üçsular, 2018). Bu nedenle ileride yapılacak çalışmalarda inme hastalarına bakım verenler için de ev düzenlemelerinin etkinliğinin araştırılabileceğini düşünmekteyiz. Bu nedenle bu çalışmaya daha fazla hasta sayısıyla ve daha uzun süre devam etmeyi planlıyoruz. Erişilebilirlik ve evrensel tasarım sadece bir amaç değil, topluma katıımını ve iyileştirme rehabilitasyon sürecini sağlayan araçlardır (Kınalı, 2020). İyileşme hastane ile sınırlı olmayan ve bazen bir ömür boyu süren uzun bir süreçtir. Erişilebilirlik ve evrensel tasarım uygulamalarının nörolojik hastalıklarda kullanımına yönelik araştırmaların artırılması gerektiğini düşünüyoruz. Günümüzde dijital cihazlar ve akıllı telefonlar, ev güvenliğini uzaktan bile sağlayabilir hale geldi. Bu nedenle, eve dönüş sürecinde bu nedenle inmeli hastalar için akıllı ev uygulamaları düşünülebilir. Engelli bireyller internet kullanımında teknik güçlük yaşamakta $(\% 91,8)$ ve bu durumun kendilerini sosyal hayattan uzaklaştırdığını $(\% 76,3)$ düşünmektedirler (Kınalı ve ark., 2017). Pandemi sürecinde bu durum engelli bireyler için daha da önemli bir hal aldı ve dijital erişilebilirliği bir zorunluluk haline getirdi (Kınalı, 2021). Bu bilgiler ışığında inme sonrası dönemde yalnızca mekansal erişilebilirlik değil, dijital erişilebilirliğin etkinliği ile ilgili çalışmalara da intiyaç olduğunu düşünüyor, gelecekte bu alanla ilgili de çalışmaların yapılmasını öneriyoruz.

\section{Etik Onay}

Bu çalışma için T.C. Adana Valiliği, İ Sağlık Müdürlüğü 27350520/799 sayılı bilimsel çalışma izni ve T.C. Çukurova Üniversitesi Tıp Fakültesi Girişimsel Olmayan Klinik Araştırmalar Etik Kurulundan, 2 Şubat 2018 Tarihli 74/15 sayılı kararı ile onay alınmıştır.

\section{Araştırmacıların Katkı Oranı}

Didem Gök Nokay: Verilerin toplanması ve yazının yazılmasında eşit katkı.

Gülşah Kınalı: Çalışmanın planlanması, verilerin analizi ve yorumlanması, yazının yazılmasında eşit katkı.

\section{Çıkar Çatışması Beyanı}

Yazarlar arasında çıkar çatışması bulunmamaktadır.

\section{Destek/Teşekkür}

Yazarlar, Adana Seyhan Devlet Hastanesine, çalışmaya katılan hasta ve hasta yakınlarına teşekkür eder.

\section{Kaynaklar}

Ahmed, S., Mayo, N. E., Higgins, J., Salbach, N. M., Finch, L., \& Wood-Dauphinée, S. L. (2003). The Stroke Rehabilitation Assessment of Movement (STREAM): A comparison with other measures used to evaluate effects of stroke and rehabilitation. Phys Ther, 83(7), 617-630. https://doi.org/10.1093/ptj/83.7.617

Çiftçi, İ., \& Çağlayan Gümüş, D. (2017). Erişilebilirlik İzleme ve Denetleme Formları. Ankara, Başak Matbaacılık.

Akulwar, I., \& Shahane, N. (2017). Perceived environmental barriers to community participation in stroke patients. IJSR, 6, 1675-1679.

Altuntaş, O., \& Kayıhan, H. (2015). Ev düzenlemelerinin yaşılıarın yaşam kalitesine etkisi. Turk J Physiother Rehabil, 26(1), 113.

Beck, A.T., Steer, R.A., \& Brown, G.K. (1996). Manual for the Beck Depression Inventory-II. San Antonio, TX: Psychological Corporation.

Bergström, A. L., von Koch, L., Andersson, M., Tham, K., \& Eriksson, G. (2015). Participation in everyday life and life satisfaction in persons with stroke and their caregivers 3-6 months after onset. $J$ Rehabil Med, 47(6), 508-515. DOI: 10.2340/16501977-1964

Cameron, J. I., Tsoi, C., \& Marsella, A. (2008). Optimizing stroke systems of care by enhancing transitions across care environments. Stroke, 39(9), 2637-2643. DOI: 10.1161/STROKEAHA.107.501064

Chun, H. Y. Y., Whiteley, W. N., Dennis, M. S., Mead, G. E., \& Carson, A. J. (2018). Anxiety after stroke: the importance of subtyping. Stroke, 49(3), 556-564. DOI: 10.1161/STROKEAHA.117.020078

Drummond, A., Whitehead, P., Fellows, K., Edwards, C., \& Sprigg, N. (2012). Occupational therapy predischarge home visits for patients with a stroke: What is national practice? $\mathrm{Br} J$ Occup Ther, 75(9), 396-402. https://doi.org/10.4276/030802212X13470263980711 
Duncan, P. W., Goldstein, L. B., Matchar, D., Divine, G. W., \& Feussner, J. (1992). Measurement of motor recovery after stroke. Outcome assessment and sample size requirements. Stroke, 23(8), 1084-1089. https://doi.org/10.1161/01.STR.23.8.1084

Ellis-Hill, C. S., \& Horn, S. (2000). Change in identity and self-concept: A new theoretical approach to recovery following a stroke. Clin Rehabil, 14(3), 279-287. https://doi.org/10.1191/026921500671231410

Fydrich, T., Dowdall, D., \& Chambless, D. L. (1992). Reliability and validity of the Beck Anxiety Inventory. J Anxiety Dis, 6(1), 55-61. https://doi.org/10.1016/08876185(92)90026-4

Garin, N., Olaya, B., Miret, M., Ayuso-Mateos, J. L., Power, M., Bucciarelli, P., et al. (2014). Built environment and elderly population health: A comprehensive literature review. Clin. Pract. Epidemiol, 10, 103-115. doi: $10.2174 / 1745017901410010103$

Hormozi, S., Alizadeh-Khoei, M., Sharifi, F., Taati, F., Aminalroaya, R., Fadaee, S., et al. (2019). Iranian version of Barthel Index: validity and reliability in outpatients' elderly. Int J Prev Med, 10, 130-135. doi: 10.4103/ijpvm.IJPVM_579_18

Huang, H. K., Lin, S. M., Yang, C. S. H., Liang, C. C., \& Cheng, H. Y. (2017). Post-ischemic stroke rehabilitation is associated with a higher risk of fractures in older women: A population-based cohort study. PloS One, 12(4), e0175825. https://doi.org/10.1371/journal.pone.0175825

Hugues, A., Di Marco, J., Janiaud, P., Xue, Y., Pires, J., Khademi, H., et al. (2017). Efficiency of physical therapy on postural imbalance after stroke: Study protocol for a systematic review and meta- analysis. BMJ Open, 7(1), e013348. http://dx.doi.org/10.1136/bmjopen-2016-013348

Keysor, J. J., Jette, A. M., Coster, W., Bettger, J. P., \& Haley, S. M. (2006). Association of environmental factors with levels of home and community participation in an adult rehabilitation cohort. Arch Phys Med Rehabil, 87(12), 1566-1575. https://doi.org/10.1016/j.apmr.2006.08.347

Kinali, G. (2017). Differencies in robotic rehabilitation according to clinic requirements. Medical Technologies National Congress (TIPTEKNO), (pp. 1-3).

Kinali, G., Bilen, Ö., Doğanay, F., \& Abakay, O. (2017). Digital accessibility in handicapped persons. Medical Technologies National Congress (TIPTEKNO) (pp. 13).

Kinali, G., \& Üçsular, F. D. (2018). Detection of early symptoms of cumulative trauma disorders among mothers of handicapped children: A pilot study. J Phys Ther Sci, 30(2), 196-200. https://doi.org/10.1589/jpts.30.196

Kınalı, G. (2020). Rehabilitasyonda Topluma Katıımın İki Anahtarı: Erişilebilirlik Ve Evrensel Tasarım. Sosyal Politika Çalışmaları Dergisi, Erişilebilirlik Özel Sayısı (1) , 105-118. DOI: 10.21560/spcd.vi.818685

Kınalı, G. (2021). Evrensel Tasarımın Kullanıldığı Alanlar, Rehabilitasyonda Evrensel Tasarım ve Herkes İçin Erişilebilirlik (ss 38-40), İstanbul: İstanbul Tıp Kitabevi. Kylén, M., Von Koch, L., Pessah-Rasmussen, H., Marcheschi, E., Ytterberg, C., Heylighen, A., \& Elf, M. (2019). The importance of the built environment in
person-Centred rehabilitation at home: study protocol. Int $J$ Environ Res Public Health, 2019, 16(13), 2409. https://doi.org/10.3390/ijerph16132409

Langhorne, P., \& Widen-Holmqvist, L. (2007). Early supported discharge after stroke. J Rehabil Med, 39(2), 103-108. DOI: 10.2340/16501977-0042

Langhorne, P., Coupar, F., \& Pollock, A. (2009). Motor recovery after stroke: A systematic review. Lancet Neurol, 8(8), 741754. DOI: 10.1016/S1474-4422(09)70150-4

Lenzi, G. L., Altieri, M., \& Maestrini, I. (2008). Post-stroke depression. Rev. Neurol, 164(10), 837-840. DOI: 10.1016/j.neurol.2008.07.010

Li, X., Xia, X., Wang, P., Zhang, S., Liu, M., \& Wang, L. (2017). Needs and rights awareness of stroke survivors and caregivers: A cross-sectional, single-centre questionnaire survey. BMJ Open, 7(10) e013210. DOI: 10.1136/bmjopen2016-013210

Marcheschi, E., Von Koch, L., Pessah-Rasmussen, H., \& Elf, M. (2018). Home setting after stroke, facilitators and barriers: A systematic literature review. Health Soc Care Community, 26(4), e451-e459. DOI: 10.1111/hsc.12518

Miller, E. L., Murray, L., Richards, L., Zorowitz, R. D., Bakas, T., Clark, P., et al. (2010). Comprehensive overview of nursing and interdisciplinary rehabilitation care of the stroke patient: A scientific statement from the American Heart Association. Stroke, 41(10), 2402-2448. DOI: 10.1161/STR.0b013e3181e7512b

Miller, K. K., Lin, S. H., \& Neville, M. (2019). From hospital to home to participation: A position paper on transition planning poststroke. Arch Phys Med Rehabil, 100(6), 1162-1175. DOI: 10.1016/j.apmr.2018.10.017

Mollaoğlu, M., Özkan Tuncay, F., \& Kars Fertelli, T. (2011). İnmeli hasta bakım vericilerinde bakım yükü ve etkileyen faktörler. DEUHYO ED, 4(3): 125-130

Norrving, B., \& Kissela, B. (2013). The global burden of stroke and need for a continuum of care. Neurology, 80(3 Supplement 2), S5-S12. doi:10.1212/WNL.0b013e3182762397

Oupra, R., Griffiths, R., Pryor, J., \& Mott, S. (2010). Effectiveness of Supportive Educative Learning programme on the level of strain experienced by caregivers of stroke patients in Thailand. Health Soc Care Community, 18(1), 10-20. doi:10.1111/j.1365-2524.2009.00865.x

Öncü, J.,Begoğlu, F., Durlanik, G., Kuran, B., \& Doğu, B. (2014). Hemiplejik hastalarda el kemik mineral yoğunluğu ölçümleri ve klinik parametrelerle ilişkisi. Türk Fiz Tıp Rehab Derg, 60(4), 282-8. DOI: 10.5152/tttrd.2014.28003

Paci, M., Nannetti, L., Casavola, D., \& Lombardi, B. (2016). Differences in motor recovery between upper and lower limbs: does stroke subtype make the difference?. Int $J$ Rehabil Res, 39(2), 185-187. DOI: 10.1097/MRR.0000000000000172

Palstam, A., Sjödin, A., \& Sunnerhagen, K. S. (2019). Participation and autonomy five years after stroke: A longitudinal observational study. PloS One, 14(7), e0219513. DOI: 10.1371/journal.pone.0219513

Reinhardt, J. D., \& Stucki, G. (2007). Rheumatoid arthritis and participation--the social animal revisited. J Rheumatol, 34(6), 1214-1216.

Rochette, A., Desrosiers, J., \& Noreau, L. (2001). Association between personal and environmental factors and the occurrence of handicap situations following a stroke. Disabil Rehabil, 23(13), 559-569. https://doi.org/10.1080/09638280010022540 
Sanford, J. A. (2012). Universal design as a rehabilitation strategy: Design for the ages. New York: Springer Publishing Company.

Santana, S., Rente, J., Neves, C., Redondo, P., Szczygiel, N., Larsen, T., et al. (2017). Early home-supported discharge for patients with stroke in Portugal: A randomised controlled trial. Clin Rehabil, 31(2), 197206. doi:10.1177/0269215515627282

Soyuer, F., Ünalan, D., \& Öztürk, A. (2007). İnme hastalarında yaş ve cinsiyetin fonksiyonel yetersizlik üzerine olan etkisi. Turgut Özal Tıp Merk Derg, 14(2): 91-94.

Sturm, J. W., Dewey, H. M., Donnan, G. A., Macdonell, R. A., McNeil, J. J., \& Thrift, A. G. (2002). Handicap after stroke: How does it relate to disability, perception of recovery, and stroke subtype? The North East Melbourne Stroke Incidence Study (NEMESIS). Stroke, 33(3), 762-768.

doi:10.1161/hs0302.103815

Sturm, J. W., Donnan, G. A., Dewey, H. M., Macdonell, R. A., Gilligan, A. K., \& Thrift, A. G. (2004). Determinants of handicap after stroke: The North East Melbourne stroke incidence study (NEMESIS). Stroke, 35(3), 715720. doi:10.1161/01.STR.0000117573.19022.66

Yavuzer, G., Sonel, B., Tuncer, S., Süldür, N. (2001) Inmeli hastalarda üst ekstremite ve el fonksiyonlarının değerlendirilmesi. Türk Fiz Tıp Der, 47(3):38-43.

Wee, J. (2009). Lysaght R. Factors affecting measures of activities and participation in persons with mobility impairment in persons with mobility impairment. Disabil Rehabil, 31 , 1633-1642. doi:10.1080/09638280902736346

Werngren-Elgström, M., Carlsson, G., \& Iwarsson, S. (2009). A 10-year follow-up study on subjective wellbeing and relationships to person-environment (P-E) fit and activity of daily living (ADL) dependence of older Swedish adults. Arch Gerontol Geriatr, 49(1), e16-e22. doi:10.1016/j.archger.2008.08.001

Wilson, C. M., Mitchell, C. L., \& Hebert, K. M. (2017). Cerebellar stroke occupational therapy and physical therapy management from intensive care unit to outpatient: A case report. Cureus, 9(12), e1949. doi:10.7759/cureus.1949

Wood, J. P., Connelly, D. M., \& Maly, M. R. (2010). 'Getting back to real living': A qualitative study of the process of community reintegration after stroke. Clin Rehabil, 24(11), 1045-1056. doi:10.1177/0269215510375901 